\title{
US public puts faith in science, but still lacks understanding
}

[WASHINGTON] Public interest in science and technology is at an all-time high in the United States, even though popular understanding of basic scientific concepts remains weak, according to an extensive study for the National Science Foundation (NSF).

But the study, published last week, reports that this understanding is still greater than that in many other countries, and that US faith in the ability of science to do good is markedly greater than that elsewhere.

The study was conducted by Jon Miller of the Chicago Academy of Sciences, and is incorporated into Science and Engineering Indicators 1998, the NSF's biennial report on national trends in science. It found that 70 per cent of Americans say they are interested in science and technology; this is the highest number ever recorded.

The number saying they were interested in science was up from 61 per cent in 1992 and 67 per cent in 1995, and now exceeds those professing interest in foreign policy ( 47 per cent) and economic policy (68 per cent). The number who considered themselves 'well informed' about scientific discoveries and new technologies had also risen sharply over the past five years, the survey found.

Miller, who has been conducting the survey for NSF since 1979, says the last finding reflects growing public familiarity with scientific ideas, partly as a result of strong science coverage in newspapers and on television. "It is a measure of how comfortable people feel with science," he says.

The survey also finds that Americans are vastly more positive about the overall impact of science and technology than those in Europe or Japan. Using a list of questions to generate an 'index of scientific promise' as a measure of positive attitudes, and an 'index of scientific reservation' to measure negative ones, the study indicates that Americans' positive impressions of science and technology have grown from an already high base.

The latest study gives the United States a 'scientific promise' index of 70 and a 'scientific reservation' index of 37 , resulting in a 'confidence ratio' between the two indices of 1.89, up from 1.76 in 1992.

Numerous studies in European countries (and in Canada) have identified a similar belief in science's promise but far greater reservations, with resulting ratios of between 1.1 and 1.3 (see graph). A 1991 study in Japan indicated that people there share Europe's reservations but have much less faith in the promise of science and technology, with a resulting confidence ratio of less than one.

Miller attributes Americans' high confi-

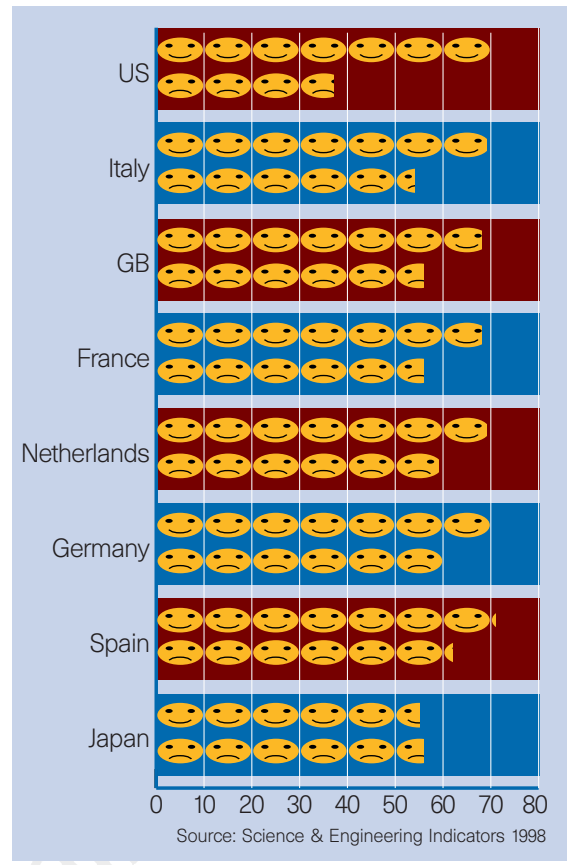

Happy days: the ratio of those seeing high 'promise' to serious 'reservations' in science is higher in the United States than elsewhere.

dence in science to its successful record in assuring national security and better healthcare, and in developing computer and telecommunications equipment. "This country has had a string of successes in science. For the average person, a lot of things have improved," he says. "And once you have a society that comes to celebrate its scientific achievements, that tends to perpetuate itself."

But the study found little improvement in the public's ability to grasp basic scientific concepts. Only 11 per cent could explain what a molecule was, while 44 per cent knew that electrons were smaller than atoms. An index based such questions gave the United States a score of 55 , similar to scores recorded in previous studies in the United Kingdom, Denmark and France, but higher than those of other European countries and Japan.

Although recent international comparisons have suggested that US schoolchildren are poor at science and mathematics, Miller believes that the reason US adults do quite well in his scientific literacy test is that 40 per cent of Americans go to college, and that nearly all of them are exposed to "at least a year" of science there. In Europe, as he points out, college students pursuing degrees other than science often get no exposure to it at all.

Miller adds that most of the public are unable to distinguish between science and technology, but says this is unsurprising. "If you asked a scientist whether the human genome project was 'science' or 'technology' you would get a good dinner-table discussion going, so you can't blame the public for being confused," he says.

Despite the strong support for science identified by the study, Miller worries that a sizeable proportion of the population still has little understanding of science.

The survey reveals that 45 per cent of respondents knew that the Earth goes round the Sun once a year. But any science educator who might lie awake at night fearing that most Americans retain the pre-Copernican view that the Sun goes round the Earth can sleep soundly: fewer than a quarter think this; the rest think the Earth goes round the Sun once a day.

Colin Macilwain

\section{University says sorry for its racist past}

[MUNICH] The University of Rostock has become the first east German university formally to apologize for removing academic titles on racial or political grounds during the Nazi era from 1933 to 1945 . The university has said that the derecognition of academic qualifications was an "arbitrary measure" that was illegal and invalid.

The university has found in its archives 15 cases of derecognition, all involving Jewish male academics. Only one of them, Georg Cohn, still had a university post at the time. The others had fled Germany earlier, and so were automatically branded as political traitors by the Nazi regime.

The university's investigations also showed that derecognition of doctorates was first proposed by German students, not by the Nazi government. In a letter sent to the Bavarian ministry of education in September 1933, the "German student body - Bavaria district" requested that the ministry strip of their doctorates "traitors who left the country". The proposal was eagerly pursued by ministries and universities all over Germany.

Angela Hartwig, head of the University of Rostock's archives, says that, when enquiries from Nature drew attention to the fact that the derecognitions had never been annulled, the university felt the need to compensate for the political injustice that had occurred during the Nazi era (see Nature 391, 112; 1998).

Quirin Schiermeier 